\title{
Pengelolaan Perioperatif Cedera Medula Spinalis Servikal karena Trauma dengan Tetraparesis Frankle C Asia
}

\author{
Wahyu Sunaryo Basuki*), Dewi Yulianti Bisri**), Siti Chasnak Saleh ${ }^{* * *}$, Himendra Wargahadibrata**) \\ Departemen Anestesiologi \& Terapi Intensif RSAD Brawijaya Surabaya, ${ }^{* *}$ Departemen Anestesiologi dan Terapi \\ Fakultas Kedokteran Universitas Padjadjaran-RSUP Dr. Hasan Sadikin Bandung ${ }^{* * *}$ Departemen Anestesiologi dan \\ Reanimasi Fakultas Kedokteran Universitas Airlangga - RSUD Dr. Soetomo Surabaya
}

\begin{abstract}
Abstrak
Cedera medula spinalis akut relatif jarang namun menjadi salah satu kejadian trauma yang berakibat fatal. Kejadian ini sering terjadi pada laki-laki dewasa muda. Kecelakaan lalu lintas merupakan penyebab utama dari kejadian ini, disusul oleh kejadian trauma di rumah, industri dan olahraga. Tujuan utama dari pengelolaan cedera medula spinalis akut adalah mencegah medula spinalis dari cedera sekunder dan memperbaiki fungsi neurologis, mencegah perubahan alignment dan menjaga stabilitas columna vertebralis untuk mendapatkan hasil pemulihan neurologis dan rehabilitasi yang maksimal. Ahli anestesi berperan besar mulai awal pengelolaan secara optimal cedera medula spinalis akut ini. Seorang laki-laki, 57 tahun, dibawa kerumah sakit karena kecelakaan sepeda motor. Pada pemeriksaan fisis, didapatkan laju nafas 24x/menit, nadi 70x/menit, tekanan darah 110/61 mmHg, perfusi baik, GCS 15, dan tetraparesis. Dalam perawatan selanjutnya, terjadi bradikardia (nadi 50-61 x/menit) dan hipotensi (tekanan darah 80-90/40-60 mmHg). Dilakukan laminoplasti dekompresi stabilisasi segera.
\end{abstract}

Kata kunci: Bradikardia, cedera medula spinalis akut, hipotensi, laminoplasti dekompresi stabilisasi

JNI 2018;7 (1): 28-35

\section{Perioperative Management Traumatic Cervical Spinal Cord Injury with Tetraparesis Frankle C Asia}

\begin{abstract}
Acute spinalis cord injury (SCI) is relatively rare but can be a fatal trauma event. Young adult men are most commonly affected. Traffic accident is a frequent cause, followed by accidents at homes, industries, and in sports. The primary goals of the management of acute SCI are to prevent secondary injury of the spinal cord, improve neurological functions, prevent disruption in alignment, and maintain the stability of the vertebral columns. These serve to achieve neurological recovery and maximal rehabilitation. Anesthesiologists play an important role in the optimal management of acute SCI. A 57-year-old man was brought to the hospital due to a motorcycle accident. Physical examination revealed respiratory rate $24 \mathrm{x} /$ minutes, heart rate $70 \mathrm{x} /$ minutes, blood pressure $110 / 61 \mathrm{mmHg}$, good perfusion, GCS 15, and tetraparesis. During hospitalization, the patient developed bradycardia (heart rate 50-61 x/minutes) and hypotension (blood pressure 80-90/40-60 $\mathrm{mmHg}$ ). Immediate decompressive laminoplasty stabilisation was performed.
\end{abstract}

Key words: Acute medula spinalis injury, bradycardia, decompressive laminoplasty stabilisation, hypotension.

JNI 2018;7 (1): 28-35 


\section{Pendahuluan}

Cedera medula spinalis akut menyebabkan morbiditas dan mortalitas yang signifikan terhadap problem sosial dan ekonomi. Cedera ini menyebabkan problem kesehatan karena memerlukan perawatan jangka panjang dan biaya yang besar. Problem psikososial pasien dan keluarga juga merupakan beban terhadap masyarakat dan negara. Lebih dari 50\% korban cedera ini tidak dapat kembali hidup secara normal, sedangkan mayoritas dari korban tersebut adalah usia 15-25 tahun yang sehat. Di Inggris angka kejadiannya $10-15$ orang per satu juta populasi pertahun dan 40000 orang hidup dengan cedera medula spinalis. Di Amerika sekitar 50-55 orang per satu juta populasi per tahun dengan total biaya rata-rata berkisar empatlima milyar dolar. Pada trauma servikal dengan cedera medula spinalis angka mortalitasnya pada 3 bulan adalah $20 \%-21 \%$. Sedangkan prediktor mortalitas independennya adalah level dari cederanya, CGS, usia dan gagal nafas. ${ }^{1-4}$

Cedera medula spinalis akut menyebabkan gangguan yang komplet atau inkomplet dari fungsi motorik, sensorik, autonomik dan reflek. Mekanisme cederanya terdiri dari cedera primer dan cedera sekunder. Ahli anetesi berperan besar pada pengelolaan cedera medula spinalis akut mulai dari tahap awal resusitasi setelah kejadian sampai tahap pengelolaan jangka panjang. ${ }^{2,4}$ Cedera pada medula spinalis ini sering menyebabkan gangguan atau disfungsi sistim respirasi dan jantung, bahkan dua hal tersebut sering menyebabkan kematian. ${ }^{1,5,6}$

Oleh karena itu pada fase primer dilakukan resusitasi untuk mencegah hal tersebut yaitu melakukan resusitasi airway dengan imobilisasi servikal spinal, breathing dan circulation dengan kontrol perdarahan dan pengelolaan syok neurogenik. ${ }^{2}$ Selanjutnya dilakukan pengelolaan pada fase sekunder yang meliputi pemberian anestesi untuk stabilisasi dari kolumna spinalis serta tindakan pembedahan untuk dekompresi atau fusi. Hal ini untuk melindungi dan mencegah kerusakan Medula spinalis lebih lanjut, menjaga struktur tulang dan stabilitasnya sehingga didapatkan pemulihan dan rehabilitasi yang maksimal. Pengelolaan anestesi meliputi pemilihan obat, memberikan oksigen yang adekuat, menjaga kondisi normokapneu, normoglikemia serta menjaga perfusi medula spinalis yang adekuat. Hipotensi sistemik akan menyebabkan cedera sekunder, sedang hipertensi, akan menyebabkan perdarahan dan edema. Pada fase sekunder dilakukan perawatan di intensive care unit karena seringkali cedera medula spinalis pada trauma terjadi sebagai multi trauma seperti cedera otak dan cedera abdomen serta yang lainnya. ${ }^{2,4}$ Pada cedera medula spinalis pada daerah servikal tinggi sering memerlukan perawatan dengan ventilator mekanik di ICU.

\section{Kasus}

Seorang laki-laki 58 tahun $60 \mathrm{~kg}$ dirujuk ke rumah sakit karena kecelakaan lalu lintas sepeda motor dengan sepeda motor. Penderita mengeluh kedua tangan dan kedua kaki lemah, kesemutan dan rasa baal, tengkuk terasa nyeri. Dari anamnesa penderita sempat pingsan dan muntah. Kejadian 12 jam sebelum masuk rmah sakit. Kelemahan kedua tangan dan kaki tidak ada sebelum terjadinya kecelakaan.

\section{Pemeriksaan Fisik}

Penderita dibawa dengan stretcher dan memakai collar neck rigid. Jalan nafas bebas, frekwensi nafas 28x/ menit dengan oksigen kanul 3 liter/ menit, $\mathrm{SpO}_{2} 98 \%$. Hemodinamik perfusi hangat kering merah. Nadi 70x/menit reguler, tekanan darah 125/70 mmhg. GCS E4 V5 M Tetraparesis pupil isokor, reflek cahaya $+/+$. Pada pemeriksaan neurologis motorik didapatkan sebagai berikut: sensorik hipoalgesia setinggi C3 - distal dermatom.

\begin{tabular}{|l|l|}
\hline 22223333 & 22222222 \\
\hline 33333333 & 33332222 \\
\hline
\end{tabular}

Reflek BPR $\downarrow \mid \downarrow$ TPR $\downarrow \mid \downarrow$ APR $\downarrow \mid \downarrow$ KPR $\downarrow \mid \downarrow$ reflek patologis (-). RT tonus spingter ani (-). Bising usus + lemah. Ronkhi dan wheezing tidak ada. 


\section{Pemeriksaaan Penunjang}

Pemeriksaan laboratorium $\mathrm{Hb}$ 10,7 g/dl, L 15.290/ ul, Ht 34,6 Vol \%, Thr 338.000/ul, BT 2 menit, CT 10 menit, PPT 13,2 detik, kontrol 12,6 detik, APTT 32,20 detik, kontrol 30,80 detik golongan darah B Rh positif. SGOT 28 U/1 SGPT 13 U/l. Ureum 37,2 mg/ dl, Sc 1,39 mg/dl. Albumin 3,50 $\mathrm{g} / \mathrm{dl}$, GDS $125 \mathrm{mg} / \mathrm{dl}$, Natrium $134 \mathrm{mmol} / \mathrm{L}$, Kalium 4,1 mmol/L, Klorida $107 \mathrm{mmol} / \mathrm{L}$. Analisa gas darah $\mathrm{pH} 7,44, \mathrm{PCO}_{2} 44,2 \mathrm{mmHg}$, $\mathrm{PO}_{2}$ 140,6 mmHg, $\mathrm{HCO}_{3} 28,6, \mathrm{O}_{2}$ saturasi 99,0, BE 2,3, $\mathrm{AADO}_{2} 42,8$.

Thorax foto pre operasi

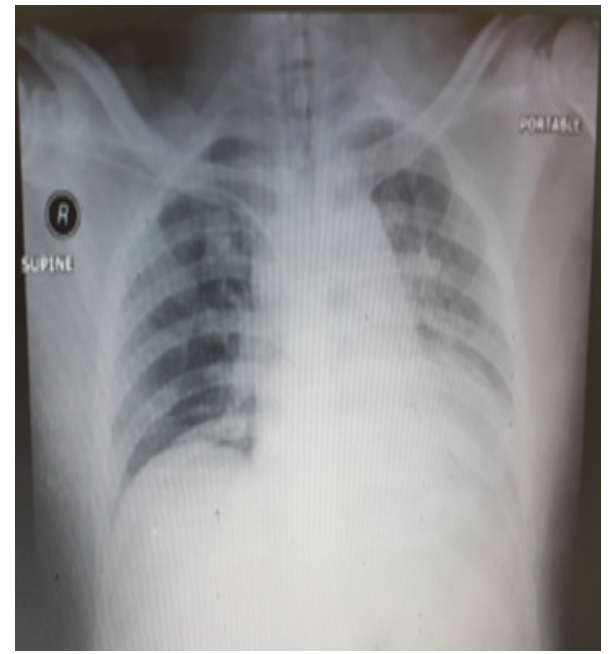

Gambar. 1 Thorax foto AP.

Kesan: Foto Thorax dalam batas Normal

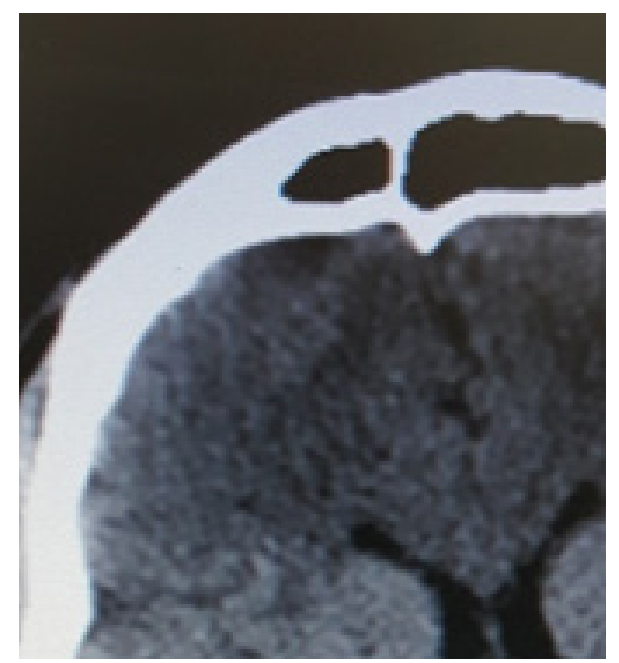

\section{Gambar 2. CT kepala}

Hasil: Kesan brain parenkim dan intrakranial lainnya normal tak tampak kelainan
MRI Cervical Pre operasi

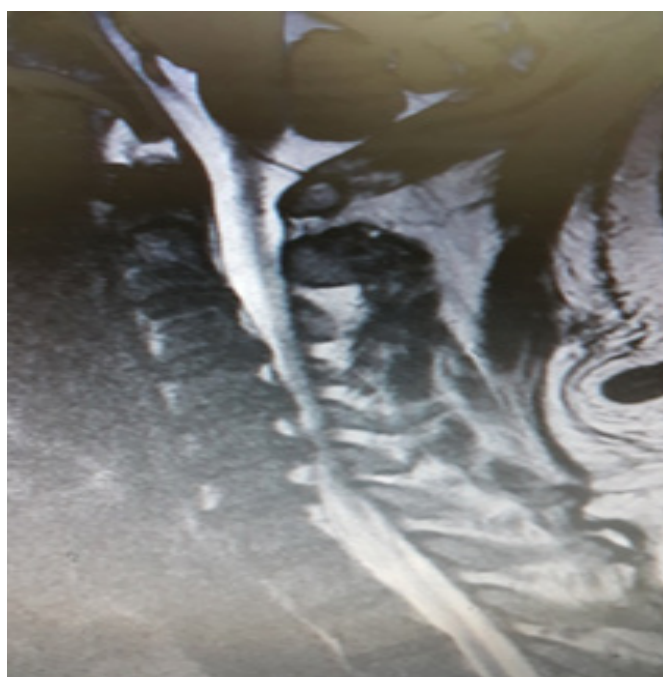

Gambar. 3.1 MRI:

Gambaran penyempitan kanalis sentralis, bulging disc, stenosis

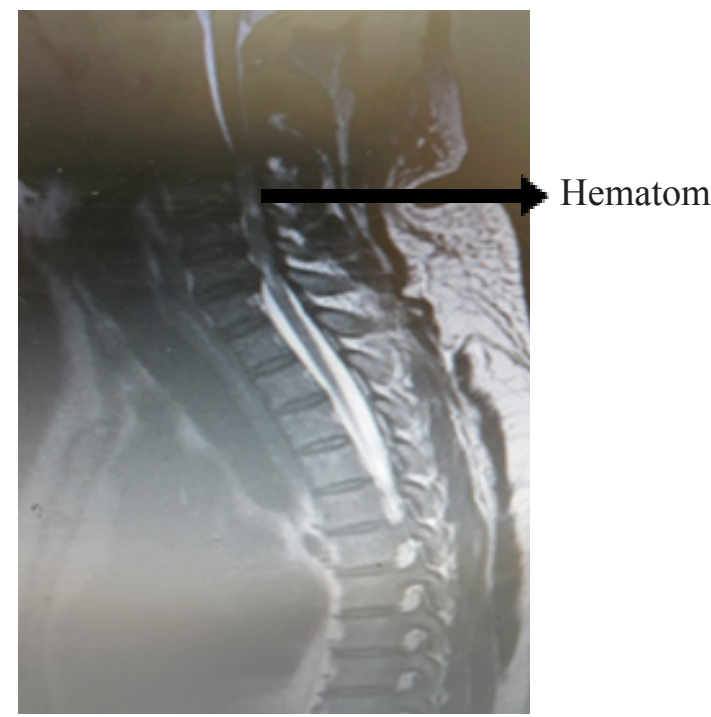

Gambaran Hematom

Secara umum terjadi penyempitan central canal mulai dari C4 s/d C6 dengan diameter ratarata 6-7 $\mathrm{mm}$. Posterior osteophytes terutama di level C4-5 (paramedian kanan dan kiri) dan C6-7 (Para median kanan dan kiri). Post trauma tampak hyperindense medula spinalis edema di level C4-5,6-7 yang secara biomekanik dapat dijelaskan akibat flexion injury dan trauma akibat posterior osteophytes di dua level di atas. discus intervertebralis: C2-3, C7-Th1: normal, C3-4: 


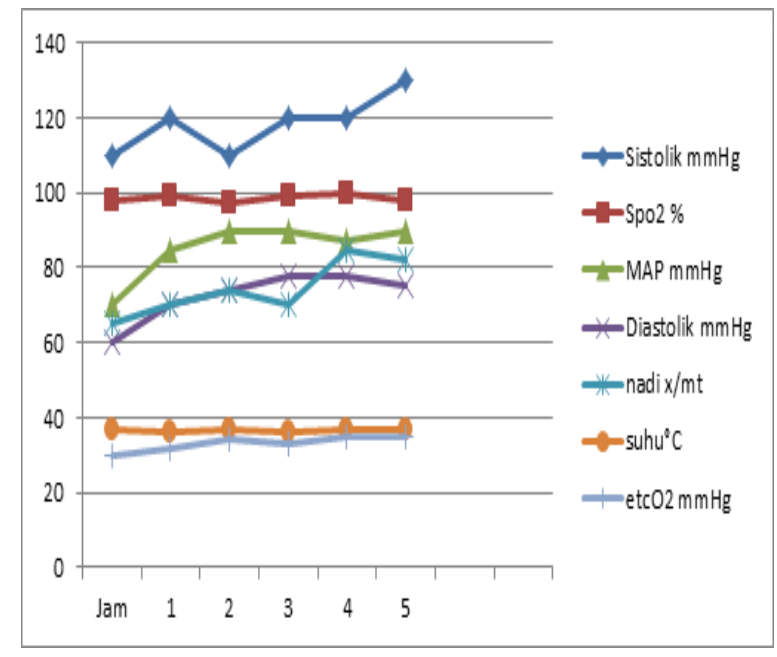

Tanda Vital selama Operasi

bulging disc ke posterior mendesak anterior thecal sac serta menyebabkan moderate stenosis foraminal canal bilateral. C4-5, 5-6: protruded disc disertai osthepyte menyebabkan moderate stenosis central canal, severe stenosis foraminal canal kanan dan moderrate kiri. C6-7: Pasien dirawat di ruang terapi intensif setelah dilakukan MRI menunggu dilakukan operasi dekompresi laminoplasti stabilisasi. Di pasang monitoring non invasif untuk tanda vital; nadi, tensi, saturasi oksigen, suhu. Diberikan oksigen kanul 3 liter permenit, cairan infus balan cairan iso osmoler $100 \mathrm{cc} / \mathrm{jam}$.

Selama di ICU terjadi nadi bradikardia $52-60 \mathrm{x} /$ menit, tekanan darah sistolik turun $80-85 \mathrm{mmHg}$ dengan MAP 50-55 mmHg. Diberikan cairan infus balan isosmoler $500 \mathrm{cc}$ cepat, sulfasatropin $0,5 \mathrm{mg}$ IV sebanyak dua kali dan dopamin $3 \mu \mathrm{g}-$ $5 \mu \mathrm{g} / \mathrm{kgBB}$. Selanjutnya penderita disiapkan ke kamar operasi dengan nadi diatas 60x/menit dan tekanan darah sistolik diatas $100 \mathrm{mmHg}$, MAP mencapai $80-85 \mathrm{mmHg}$.

\begin{tabular}{|ll|ll|}
\hline 3333 & 3333 & 3333 & 2222 \\
\hline 3333 & 3333 & 3333 & 3333 \\
\hline
\end{tabular}

\section{Pengelolaan Anestesi}

Transportasi ke kamar operasi dengan tetap mempertahankan airway, breathing, circulation $(A B C)$ kontrol spine. Monitor non invasif tetap terpasang. Intubasi dilakukan dengan tetap mempertahankan posisi secara manual, colar neck tidak dilepas. Laringoscope yang dipergunakan adalah McCintosh. Induksi dengan propofol $2 \mathrm{mg} / \mathrm{kg}$ dosis titrasi, vecuronium, $0,10 \mathrm{mg} / \mathrm{kg}$ $\mathrm{BB}$, fentanyl $2 \mathrm{mg} / \mathrm{kgBB}$. Selama proses intubasi tekanan darah terpasang stat, tidak ada gejolak nadi dan tekanan darah selama proses intubasi. Nadi berkisar $65-80 x /$ menit dan tekanan darah 105-115/55-70 mmHg, Suhu rektal 36,9 $9^{\circ} \mathrm{C}$. Setelah dilakukan pemasangan nasogastrik tube dan pemasangan tampon hipofaring untuk fiksasi kemudian dilakukan pemasangan arteri line dan vena sentral. Kateter urine sudah terpasang Posisi pasien untuk operasi adalah posisi prone, diposisikan setelah dilakukan perlindungan terhadap daerah mata, wajah, serta setelah vital sign baik dan stabil. Dilakukan pemeriksaan

\begin{tabular}{|ll|ll|}
\hline 3333 & 3333 & 3333 & 3333 \\
\hline 5555 & 5555 & 5555 & 5555 \\
\hline
\end{tabular}

kondisi torak, perut apakah sudah bebas. Rumatan anestesi dilakukan dengan propofol $4 \mathrm{mg} / \mathrm{kg} \mathrm{bb} / \mathrm{jam}$, sevoflurane $0,8 \%-1,5 \%$ volume, vecuronium $0,03-0,05 \mathrm{mg} / \mathrm{kgBB} / \mathrm{jam}, \mathrm{O}_{2} \quad 50 \%$ dengan $\mathrm{O}_{2} /$ udara dan $\mathrm{O}_{2}$ murni. Fentanyl lug/ $\mathrm{kg}$ bb diberikan sebanyak 3 kali selama operasi. Rumatan cairan yang dipergunakan adalah ringerfundin. Monitoring yang dilakukan selama operasi berlangsung adalah EKG, $\mathrm{ABP}, \mathrm{SpO}_{2}$, $\mathrm{EtCO}_{2}$, suhu rektal, urine.

Operasi berlangsung selama 5 jam. Selama operasi dilakukan rumatan anestesi kontrol ventilasi dengan frekuensi $13 \mathrm{x} /$ menit, volume tidal $8 \mathrm{cc} / \mathrm{kg}$ bb sehingga tercapai minute volume 6,2 liter, PEEP 3. Dengan memberikan Dopamin 3-5 microgram $/ \mathrm{kgBB}$ didapatkan MAP 75-90 $\mathrm{mmHg}$, tekanan darah sistolik $105-130 \mathrm{mmHg}$ dan laju nadi $65-85 x$ per menit. $\mathrm{EtCO}_{2}$ berkisar antara 32-36, serta suhu rektal 36,6-37,2. Cairan balans isosmoler yang masuk sebanyak $1200 \mathrm{cc}$ sedang produksi urin sebanyak $500 \mathrm{cc}$ dengan perdarahan $200 \mathrm{cc}$, penderita dirawat di ruang ICU dengan ventilator. Obat pasca operasi yang diberikan adalah analgetik petidin $50 \mathrm{mg} 1 . \mathrm{m}$; parasetamol 1 gr, Omeprazole $20 \mathrm{mg}$, odansetron $4 \mathrm{mg}$, intravena. 


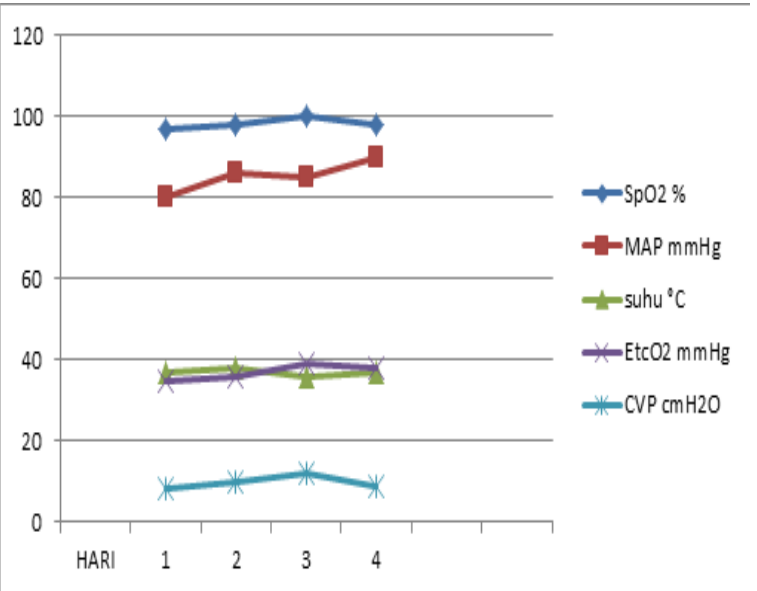

Gambaran Fungsi Vital di ICU

\section{Perawatan di ICU}

\section{Hari 1 di ICU}

penderita dirawat dengan ventilator mode PSIMV RR 13x, $\mathrm{FlO}_{2} 40 \%$, PC I2, TV 480500 cc, I:E $1: 2$, triger 1, PEEP 3, EtCO $230-35$ dengan $\mathrm{SpO}_{2} 97-99 \%$, MAP $80-90 \mathrm{mmHg}$, CVP 8-11 dan suhu rektal 36,8-37,1, nadi 65$78 \mathrm{x} /$ menit irama sinus. Terapi yang diberikan balan cairan isosmoler $1500 \mathrm{cc}$ dan $\mathrm{NaCl} 0,9 \%$ 500 cc selama 24 jam, serta sonde D5 \% 6x50 cc, antibiotik, parasetamol 3x $1 \mathrm{gr}$, omeprazole $20 \mathrm{mg}$, dopamin 5-8 mikro/kgbb. Pemeriksaan laboratorium $\mathrm{Hb} 11,8 \mathrm{~g} / \mathrm{dl}$, Ht 35,6 vol\%, Thr $18400 / \mathrm{ul}, \mathrm{Na} 136 \mathrm{mmol} / \mathrm{L}, \mathrm{K} 3,4 \mathrm{mmol} / \mathrm{L}, \mathrm{NaCl}$ $104 \mathrm{mmol} / \mathrm{L}$, GDS $113 \mathrm{mg} / \mathrm{dl}$, analisa gas dalam $\mathrm{pH} 7,36, \mathrm{PCO}_{2} 44 \mathrm{mmHg}, \mathrm{PO}_{2} 108 \mathrm{mmHg}$, $\mathrm{HCO}_{3} 28,4 \mathrm{mmol} / \mathrm{L}, \mathrm{BE} 2,1 \mathrm{mmol} / \mathrm{L} \mathrm{AADO} 28$. Suara nafas tambahan tidak ada, GCS E4 VxM6 tetra paresis, bising usus positif perut tidak kembung. Status neurologi: sensoris hipoalgesi positif, reflek fisiologis menurun dan tonus spingter ani negatif.

\section{Hari II-III}

Suport ventilator mulai diturunkan dari PSIMV RR $13 \mathrm{x} /$ menit menjadi sampai RR 8 x/menit dengan PS 6, $\mathrm{FiO}_{2}$ menjadi $30 \%$. Laju nafas yang keluar 16-20 x/menit, TV 480-590 cc, minute volume 7,6-8,6 tanda-tanda vital relatif sama, bising usus positif, tidak ada retensi lambung produksi urine cukup. Makanan cair personde diberikan 6x100 cc.
Tabel 1. Indikasi Ventilasi Mekanik

\begin{tabular}{ll}
\hline Parameter & Indikasi \\
\hline Ekspirasi maksimal & $<+20 \mathrm{cmH}_{2} \mathrm{O}$ \\
Inspirasi Maksimal & $<-20 \mathrm{cmH}_{2} \mathrm{O}$ \\
Kapasitas Vital & $<15 \mathrm{~mL} / \mathrm{Kg}$ \\
$\mathrm{PaO}_{2} \mid \mathrm{FIO}_{2}$ & $<250$ \\
$\mathrm{Thorax}$ foto & Atelectasis $\mid$ Infiltrates \\
\hline $\begin{array}{l}\text { Sumber: G S Umamaheswara Rao: Indian Journal Of } \\
\text { Anaesthesia, February 2008 }\end{array}$
\end{tabular}

\section{Hari IV}

Tanda-tanda vital baik tidak panas. Mode ventilator CPAP PS 8, respon pernafasan RR 1824x/menit. Volume Tidal $500-590$ cc $\mathrm{EtCO}_{2} 30$ - $33 \mathrm{mmHg}, \mathrm{SpO}_{2}$ 98-100\%,dengan kemampuan batuk kuat dan status neurologis membaik.

Kesemutan berkurang, baal membaik. Analisis gas darah $\mathrm{pH} 7,46, \mathrm{PCO}_{2} 34,8 \mathrm{mmHg}, \mathrm{PO}_{2} 190$ $\mathrm{mmHg}, \mathrm{HCO}_{3} 24,8 \mathrm{mmol}$, BE $2,9 \mathrm{mmol} / \mathrm{L}$, $\mathrm{AaDO}_{2} 98$.

\section{Hari V}

Penderita sadar baik, MAP 80-90 $\mathrm{mmHg}$, tekanan darah 105-135/65-72 mmHg, $\mathrm{EtCO}_{2} 32$, $\mathrm{SpO}_{2} 98 \%$, suhu $36,8^{\circ} \mathrm{C}-37,1^{\circ} \mathrm{C}$.

Dilakukan ekstubasi, diberikan oksigen masker $6 \mathrm{Lt} /$ menit.

\section{Hari ke VIII}

Pasca operasi penderita pindah ke ruang perawatan, hari ke 30 pulang dengan GCS 15, status neurologis sensoris hipoalgesia negatif (normal), reflek fisiologis normal, tonus spingter ani baik.

\section{Pembahasan}

Cedera medula spinalis karena trauma banyak terjadi dan sering menyebabkan morbiditas dan mortalitas. Hal ini terutama karena terjadi disfungsi sistim respirasi dan kardiologik. Cedera medula spinalis primer terjadi pada saat terjadinya trauma, sedangkan cedera sekunder berlangsung beberapa menit maupun beberapa hari setelahnya. Disfungsi respirasi pada akhirnya menyebabkan hipoksemia sedang disfungsi kardiologik yang berupa bradikardi, hipotensi sistemik karena syok 
spinal atau karena hipovolemi akan menyebabkan aliran darah spinal menurun sehingga tekanan perfusi spinal akan terganggu. Hal itu semua akan menyebabkan cedera sekunder. ${ }^{2,3,5-7}$ Cedera medula spinalis servikal tinggi menyebabkan gangguan sistem respirasi, kardiologik, dan fungsi autonom. Gangguan atau disfungsi ini sering memerlukan perawatan dengan ventilator mekanik dan terapi farmakologik. ${ }^{5-9}$ Penanganan pasien cedera medula spinalis pada fase awal atau inisial fase resusitasi adalah melakukan ABC control Spine. Mengamankan jalan nafas, memberikan oksigen yang adekuat serta menjaga tekanan darah sistolik dan MAP yang mencukupi sehingga tidak terjadi cedera sekunder. ${ }^{2,4,7}$

Pada pasien ini GCS 15, airway dan kontrol spinenya dijaga dengan memasang colar neck dan meletakkan pasien pada stretcher. Bila tidak ada colarneck bisa digunakan 2 bantal pasir kanan kiri kepala. Untuk oksigenasi diberikan oksigen kanul 2-3 liter/menit, sedang untuk mencegah hipovolema diberikan koreksi dengan cairan kristaloid balan cairan iso osmoler $500 \mathrm{cc}$ cepat dan diberikan pemberian sulfas atropin 0,5 $\mathrm{mg}$ intravena untuk mengatasi bradikardia, serta pemberian dopamin untuk mengatasi hipotensi karena syok spinal. Hipoksi dan hipofolemi pada pasien ini harus cepat diatasi karena untuk mencegah terjadinya cedera sekunder. Induksi dan intubasi pada pasien cedera medula spinalis servikal pada trauma memerlukan keterampilan dan kehati-hatian, karena trauma mekanik pada saat suction trakea, tindakan laringoskopi, intubasi endotrakea, dapat menyebabkan bradikardia sampai asistole., ${ }^{4,7,8}$

Menjaga alignment selama induksi intubasi akan mencegah cedera mekanik lanjutan, hal ini memerlukan tehnik dan keterampilan dari ahli anestesi. Colar neck tetap dipasang, dan manipulasi pada leher harus dilakukan seminimal mungkin. Dilakukannya posisi manual in line pada intubasi ini akan memperkecil terjadinya cedera pada saat intubasi. ${ }^{7}$ Untuk menjaga dan mencapai MAP $85-90 \mathrm{mmHg}$ dan tekanan sistolik diatas $90 \mathrm{mmHg}$ maka dilakukan pemberian propofol $2 \mathrm{mg} / \mathrm{kgbb}$, fentanyl, secara titrasi serta dopamin tetap diberikan secara kontinyu. Obat relaksasi otot yang diberikan adalah vekuronium karena mempunyai efek vagolitik dan histamin release yang minimal sehingga stabilitas kardiologi terjaga. ${ }^{7}$ Pada pasien ini sebelum dilakukan posisioning dilakukan pemasangan kateter vena sentral dan arteri line, nasogastrik tube, dan tampon hipofaring untuk fiksasi pipa endotrakeal. Pelaksanaan pengaturan posisi prone pasien dilakukan dengan cara log roll menjaga posisi in line serta menjaga stabilitas hemodinamik karena disfungsi kardiologik yang terjadi seperti terjadinya hipotensi ortostatistik. Dilakukan perlindungan terhadap mata, mencegah distensi lambung dengan membuka NGT, menjaga abdomen yang bebas serta menjaga dari cedera syaraf perifer. Pada cedera medula spinalis yang tinggi seperti servikal 3, servikal 4 atau servikal 5 menyebabkan gangguan sistim respirasi yang terjadi karena kelumpuhan otot inspirasi, ekspirasi, juga diapragma, serta kemampuan batuk. Ventilasi mekanik untuk tindakan anestesi disesuaikan dengan disfungsi yang terjadi yaitu disfungsi respirasi, kardiologik dan autonom yang terjadi pada pasien ini. Frekuensi nafas yang diberikan $13 x \mid$ menit dengan tidal volume $8 \mathrm{cc} / \mathrm{kg}$ bb, sehingga minute volumenya 6,2 liter. $\mathrm{FiO}_{2} 50 \%$ dengan oksigen air dan oksigen murni. Diberikan PEEP untuk menjaga alveoli, dengan tetap menjaga hemodinamik. Pemilihan obat anestesi adalah propofol $4 \mathrm{mg} / \mathrm{kg} / \mathrm{BB} / \mathrm{jam}$ dan sevoflurane $1 \%$ volume - $1,5 \%$ volume, serta obat vekuronium $3 \mathrm{mg} / \mathrm{jam}$. Obat-obat anestesi tersebut dipilih untuk menjaga stabilitas hemodinamik serta mempertahankan tekanan medula spinalis perfusi dan menurunkan laju metabolisme. ${ }^{10,11}$ Dipilih kombinasi propofol dan sevoflurane untuk menjaga kedalaman anestesi dan menjaga gejolak hemodinamik. Dopamin diberikan sebanyak 3-8 mikro/kgBB selama berlangsungnya operasi tekanan darah pada MAP dipertahankan antara 80-90 mmHg. Pada setiap waktu operasi kondisi normoglikemi normotensi, dan normovolemi dijaga dengan memberikan cairan rumatan kristaloid iso osmoler ringerfundin $2 \mathrm{cc} / \mathrm{kg} \mathrm{bb} /$ jam. Kondisi normo kapni dipertahankan dengan mengatur ventilasi mekanik sehingga tercapai $\mathrm{PaCO}_{2}$ sekitar $35 \mathrm{mmHg}$ dan pada operasi ini dipasang monitor $\mathrm{EtCO}_{2}$ 30-35. Monitor suhu dipasang di rektal dengan mempertahankan suhu antara $36,6-37,1^{\circ} \mathrm{C}$. Operasi berlangsung selama 
lima jam, dilanjutkan perawatan di ICU dengan ventilator mekanik, karena pada pasien ini terjadi gangguan saraf motorik, sensorik serta autonom karena cederanya. Cedera medula spinalis pada daerah servikal yang tinggi memerlukan bantuan ventilasi mekanik. Berat ringannya disfungsi respirasi tergantung dari level lesi spinalnya. Lesi dibawah $\mathrm{C} 4$ masih ada pengaturan respirasi volunter. Gangguan fungsi otot intercostal menyebabkan gerakan paradoksal keatas dari thorak selama inspirasi; dan ekspansi yang kurang selama inspirasi serta tidak stabilnya rongga thorak selama ekspirasi menyebabkan retensi sekresi, infeksi paru, edema paru, dan gagalnya ventilasi alveolar. Indikasi untuk melakukan ventilasi mekanik dapat dilakukan dengan beberapa parameter seperti pada tabel. ${ }^{12}$

Selama dirawat di ICU dengan ventilator dan dengan monitoring invasif maupun non invasif pasien menunjukkan tanda-tanda vital yang baik dan ada perbaikan status neurologis. Fungsi autonom juga membaik dengan fungsi gaster dan peristaltik usus yang baik serta tonus sphingster ani yang mulai timbul meskipun lemah. Penderita mulai dilakukan weaning ventilator untuk mencegah terjadinya komplikasi dari ventilator seperti pneumonia, prolong ventilator. Dalam hal ini weaning perlu hati-hati karena bila terjadi prematur akstubasi maka harus dilakukan reintubasi. Ada beberapa kriteria untuk ekstubasi yaitu: tidak panas, tanda vital baik, VC $15 \mathrm{ml} /$ $\mathrm{kgBB}$, inspiratory force $>-24 \mathrm{cmH}_{2} \mathrm{O}$, Respirasi stabil selama 24 jam, $\mathrm{PaO}_{2}>75, \mathrm{PCO}_{2} 35-45$, pH 7.35-7,45, tidak menggunakan PEEP, $\mathrm{FiO}_{2}$ tidak lebih dari $25 \%$ dan sekret bisa dikeluarkan, kondisi umum baik selama 24 jam, thorax foto baik, secara psikologis baik dan bisa bekerja sama. ${ }^{12}$ Kriteria tersebut tidak semua dilakukan seperti pemeriksaan vital capacity. Kondisi pasien yang relatif baik selama pasca operasi dimungkinkan karena pengelolaan perioperatif dan tindakan pembedahan yang segera dilakukan. Resusitasi ABCs yang dilakukan adalah untuk mencegah hipoksia dan hipotensi yaitu dengan menjaga tensi sistolik diatas $90 \mathrm{mmHg}$ dan MAP mencapai $85-90 \mathrm{mmHg}$.

Hal itu akan menyebabkan tekanan perfusi spinal tetap baik. Mengatasi disfungsi respirasi dilakukan dengan memberikan ventilasi mekanik dan farmakologik. Disfungsi kardiologik, gangguan autonom diberikan obat-obat farmakologik. ${ }^{13-15}$ Obat methyl prednisolon karena tidak diberikan karena tidak terbukti membeikan hasil yang baik tetapi menyebabkan infeksi dan gangguan lambung. ${ }^{16,17}$

\section{Simpulan}

Pengelolaan perioperatif anestesi pada pasien laki-laki 57 Th dengan cedera traumatik medula spinalis servikal tinggi Frankle C Asia pada pasien ini dilakukan dengan cepat tepat dan baik yang sesuai dengan pedoman tahapan fase penanganan anestesi mulai fase primer sampai fase long term. Perawatan cedera medula spinalis servikal tinggi pada pasien ini memerlukan ventilator mekanik yang dapat dilakukan weaning relatif cepat dengn perbaikan status neurologis disfungsi respirasi, kardiologik dan perbaikan fungsi autonom yang cepat. Hal ini dimungkinkan karena pengelolaan anestesi yang baik cepat dan tepat akan memberikan status neurologis bisa berjalan.

\section{Daftar Pustaka}

1. Van Middendorp J J, Goss B, Susan U, Atresh S, Williams RP, Schuetz M. Diagnosis and prognosis of traumatic spinal cord injury. Global Spine J 2011; 1: 1-8.

2. Wirasinghe V, Grover S Ma D, Vizcaychipi M. Anaesthetic management of patients with acute spinal injury. The Internet Journal of Anesthesiology. 2010;30 (1).

3. Yilmaz T, Turan Y, Keles A. Pathopysiology of the spinal cord njury. Review article. Journal of clinical and experimental Investigation.2014;5(1): 131-6.

4. Elif C, Copuroglu C, Sahin SH, Ciftdemir M. Anaesthesia management in spinal cord injury patients. The Journal of Turkish Spinal Surgery. 2015;26(2): 173-6.

5. Brown R, Anthony DF, Jeanette HD, Eric G. 
Respiratory dysfunction and management in spinal cord injury. Respircar. 2006 August; $51(8)$ : 835-87.

6. Grigorean VT, Sandu AM, Popescu M, Iacobini MA, Stoian R, Neascu C, Pop F. Cardiac dysfunctions following spinalcord injury. Journal of Medicine and Life.2009; 2(2): 133-45.

7. StierR,AsgarzadiefG, ColeDJ. Neurosurgical diseases and trauma of spine and spinal cord: anaesthetic considerations. Dalam: Cotrel JE, Patel, eds. Cottrel and Piyush Neuro anesthesia, 6th Ed. Philadelphia. 2017, 351409.

8. Alexander F, Daniel HJ, Spinal cord injury: evidence based medicine, diagnosis, treatment, and complication. Dalam: Layon JA, Gabrielli A, William FA. eds. Texbook of Neuro Intensive Care. 2nd Edition. London: Springerve-Verlag 2013, 619-41.

9. Ryken TC, Hurlbert RJ, Hadley MN, Aarabi B, Dhail SS, Gelb DE. The acute cardio pulmonary management of patient with spinal cord injuries. Neuro surgery. 2013; 72(3):84-92.

10. Rao USG. Anaesthetic and intensive care management of traumatic cervical spine injury. Indian Journal of anaesthesia. 2008; 52 (1): 13-22.
11. Veale P, Lamb J. Anesthesia and acute spinal cord injury. Br J Anaesth. 2002; 5(2) 139-43.

12. Berlly M, Shem K. Respiratory management during the first five days after spinal cord injury. J spinal Cord Med 2007; 30: 309-18.

13. Neil D, Armagan D. Anesthetic consideration in acute spinal cord trauma. Int J Crit ill Inj Sci. 2011; 1 (1)

14. Berlowitz DJ, Wadsworth B, Ross J, Respiratory problems and management in people with spinal cord injury. Breathe 2016; 12(4):328-40.

15. Michelle D, Mckinlay J. Cervical cord injury and critical care. Continuing Education in Anesthesia, Critical Care and Pain. 2009;9(3):82-6.

16. Botelho RV, Daniel RW, Boulosa JLR, Colli BO, de lucena Farias R, Moraes OJS, et al. Effectiveness of methyl prednisolone in acute spinal cord injury. A systemic review of randomized controlled trials. Rev Assoc Med Bras 2009; 2010; 56 (6): 729-37.

17. Hurlbert RJ. Strategies of medical intervention in the management of acute spinal cord injury. Spine 2006;31(2): 516-21. 